\title{
BIODIVERSITY Designing a conservation plan for RESEARCH protecting the habitat for giant pandas in the Qionglai mountain range, China
}

Weihua $\mathrm{Xu}^{1}$, Zhiyun Ouyang ${ }^{1 \star}$, Andrés Viña ${ }^{2}$, Hua Zheng ${ }^{1}$, Jianguo Liu ${ }^{2}$ and Yi Xiao $^{1}$

${ }^{1}$ Key Laboratory of Systems Ecology, Research Center for Eco-Environmental Sciences, Chinese Academy of Sciences. Shuang Qing Road 18, Haidian District, PO Box 2871. Beijing 100085, China; and ${ }^{2}$ Center for Systems Integration and Sustainability, Department of Fisheries and Wildlife, Michigan State University, East Lansing, Michigan 48824, USA
${ }^{*}$ Corresponding author. Zhiyun Ouyang, Key Laboratory of System Ecology, The Research Centre for Eco-Environmental Sciences, The Chinese Academy of Sciences, PO Box 2871, Beijing 100085, China. Tel.: 0086-10-62849191; Fax: 0086-10-62943822; E-mail: zyouyang@mail.rcess.ac.cn

\begin{abstract}
Population viability of the giant panda (Ailuropoda melanoleuca) is threatened by small population sizes in scattered isolated habitat areas. Designing a conservation plan for protecting and connecting the fragmented habitat will improve the chances for survival of this endangered species. For such a plan, this study assessed the overall habitat suitability for the species in the Qionglai mountain range (Sichuan, China) using Landsat TM imagery acquired in 2001, geographical data, field surveys, and information acquired in previous researches. Results show that the habitat is separated by roads and rivers, as well as by human settlements and cropland areas, into four main habitat blocks. Overlapping these four habitat blocks with the current nature reserve network reveals that only $36 \%$ of the total habitat is protected within nature reserves. Thus, the current nature reserve network is failing to preserve essential habitat for dispersal and genetic exchange. In this study, five key areas and four linkage areas were identified and suggested as nature reserves and/or corridors. These areas, together with the six currently established nature reserves in the mountain range, will form a conservation unit for facilitating the exchange of giant panda individuals among previously isolated habitat blocks. Policies recently implemented by the Chinese government, including the Natural Forest Conservation Program (NFCP) and the Grain-to-Green Program (GTGP), could aid in the formation of such a conservation unit.
\end{abstract}

\section{Keywords}

Ailuropoda melanoleuca, conservation planning, habitat assessment, habitat fragmentation, geographic information system (GIS), remote sensing.

\section{INTRODUCTION}

The giant panda (Ailuropoda melanoleuca) once ranged throughout most of the lowlands of eastern and southern China, northern Vietnam, and northern Myanmar (Pan et al., 2001). Today this range is reduced to approximately 24 isolated populations distributed across six mountain ranges in the biologically rich temperate deciduous and coniferous montane forests, at the edge of Tibetan plateau (China's Ministry of Forestry \& WWF, 1989; Loucks et al., 2001). Currently, there are around 1500 individuals in the wild and a network of 40 nature reserves has been established within the panda's geographical range (Xinhuanet, 2004). Although the number of giant panda individuals seems to have increased (as compared to the 1100 individuals reported in the 2nd National Survey of Pandas and Habitat (NSPH) carried out between 1985 and 1988), their distribution is discontinuous and population density varies in different mountain ranges (State forestry administration of China, 2004). If fragmentation of the habitat and population isolation continues, the long-term viability of the species will be heavily threatened, because small populations of giant pandas have greater probability of going extinct by inbreeding depression. For instance, research in Wolong Nature Reserve found that the three subpopulations of 30-45 pandas within the reserve have more than a 10 -fold chance of extinction by 2100 if they remain isolated from each other (Yan et al., 2000).

Around $40 \%$ of the entire giant panda population is not protected by the nature reserve network (Xinhuanet, 2004). If the remaining habitat outside the existing nature reserve network cannot be properly protected, it may be reduced in area and fragmented into small islands by the pressure of different human activities (e.g. road construction, agricultural expansion, 
fuelwood collection). This potential loss and fragmentation of the remaining habitat outside the nature reserve network will further isolate the panda population inside nature reserves. Therefore, a large-scale habitat analysis is needed for the comprehensive conservation of the giant pandas in the wild.

The Qionglai mountain range is the region where the first giant panda was scientifically discovered and is currently home to about $30 \%$ of the entire wild panda population ( $\mathrm{Hu}, 2001)$. Six nature reserves are located within its boundaries, with Wolong and Fengtongzhai administrated at the national level and Caopo, Anzihe, Heishuihe, and Labahe administrated at the provincial level (Gong \& Yu, 2003). Systematic research on giant panda started during the late 1960s, including studies on behaviour, habitat requirements, home range, habitat assessment, and population viability, among many others (Reid et al., 1989; Hu 1990; Liu et al., 1999; Hu, 2001). Nevertheless, most of these studies were carried out within individual nature reserves and did not provide information at the scale of entire mountain ranges $(\mathrm{Hu}$, 1990; Ouyang et al., 2001; Linderman et al., 2005). However, many threats derived from human activities (e.g. road construction, agricultural expansion, fuelwood collection) or from natural processes (e.g. bamboo flowering, forest fires) often impact panda habitat at large scales, and research performed at the level of nature reserves might not provide full answers to conservation issues brought by these large-scale threats (Loucks et al., 2003). Therefore, habitat assessments at the scale of entire mountain ranges are needed.

The Chinese government increased its commitment to environmental protection and initiated six environmental programs in recent years (State Forestry Administration of China, 2005). Among them, the National Forest Conservation Program (NFCP) and the Grain-to-Green Program (GTGP) show potential for restoring and expanding the habitat for the giant panda. NFCP, which was implemented after the extensive flooding in 1998, bans the harvesting of natural forests and provides economic incentives to local households for policy enforcement. GTGP was implemented in 1999 with the aim of controlling soil erosion by restoring hillside agricultural lands into forests and grasslands. The GTGP calls for local communities to receive grain subsidies and seedlings for planting forests. Farmers also receive a cash subsidy proportional to the amount of land converted (Zhu \& Feng, 2002). Research in Wolong Nature Reserve had found that implementation of these programs is benefiting panda habitat (Liu et al., 2004). However, these programs are carried out statewide, and methods of implementation as well as their effectiveness vary among different areas, as well as between the inside and the outside the nature reserves. In addition, forests are conserved or planted mainly for economic purposes (e.g. future timber harvest) and panda habitat conservation still remains poorly integrated into these programs, particularly in those areas outside nature reserves (Zhu \& Feng, 2002; Gong, 2003). Thus, effective measures should to be taken in order to integrate both panda habitat conservation and restoration into these programs. In sum, these programs provide the opportunity to restore habitats between different fragments, and making full use of this opportunity can remove isolation, and move giant panda conservation from individual reserves to aggregated habitat conservation units across the entire Qionglai mountain range, as well as in other mountain ranges comprising the entire giant panda geographical range.

In this paper, we describe a habitat assessment for the giant panda carried out across the entire Qionglai mountain range, based on satellite imagery, fieldwork, and results obtained by previous researches. We emphasize on the spatial distribution patterns of the habitat and contribute to the design of a mountainrange-wide conservation plan for the species by: (1) identifying broad fragmentation patterns, (2) providing insights for the identification of key conservation areas and corridors, and (3) providing a framework for further detailed habitat assessments.

\section{METHODS}

\section{Study area}

The Qionglai mountain range is the transition area between the Tibetan plateau and the western part of the Sichuan plain, extending approximately $250 \mathrm{~km}$ from north to south at the centre of Sichuan Province (between $102^{\circ} 16^{\prime}$ and $104^{\circ} 10^{\prime}$ longitude and $29^{\circ} 49^{\prime}$ and $31^{\circ} 31^{\prime}$ latitude, and comprising eight counties with a total area of around 1,435,000 ha; Fig. 1). Its highest peak, the Siguniang Mountain, has an elevation of around $6250 \mathrm{~m}$. The east-facing slopes of the mountain range drain into the Min River and the west-facing slopes drain into the Dadu River. Both rivers are branches of the Yangtze River.

There are six major vegetation/elevation zones in the Qionglai mountain range: (1) low elevation zone (below $1900 \mathrm{~m}$ ) dominated by arid shrubs, with understorey bamboo species including Fargesia angustissuma and Fargesia robusta. These species provide food for the giant pandas during the winter months. (2) Middle to low elevation zone (1900-2400 m) dominated by subtropical evergreen and deciduous broadleaf forests, with understorey bamboo species including F. angustissima, Chimonobambusa szechuanensis, Chimonobambusa pachystachys, F. robusta, and Yushania brevipaniculata. These species provide food for the giant pandas during the winter and spring months. (3) Middle-elevation zones (2400-2900 m) dominated by coniferous forests, with understorey bamboo species such as F. robusta and Y. brevipaniculata. This zone is the altitudinal belt where giant pandas remain during most of the winter months. (4) High elevation zones (2900-4100 m) dominated by subalpine coniferous forests, with the understorey dominated by the bamboo species, Bashania fangiana. This zone is where the giant pandas remain during the summer and autumn months. (5) Higher elevations (3900-4200 $\mathrm{m}$ ) are dominated by scrub meadows and alpine talus vegetation, and (6) permanent snow belts (above $4400 \mathrm{~m}$ ). No bamboo is distributed in these two high elevation zones.

In addition to the giant pandas, the diverse forests of the Qionglai mountain range support many different kinds of wildlife species (e.g. Phinopithecus roxellanae, Budorcas taxicolor, Cervus albirostris, Panthera unica, Davidia involucrate, Tetracentron sinense, Cercidiphyllum japonicum), some of which 


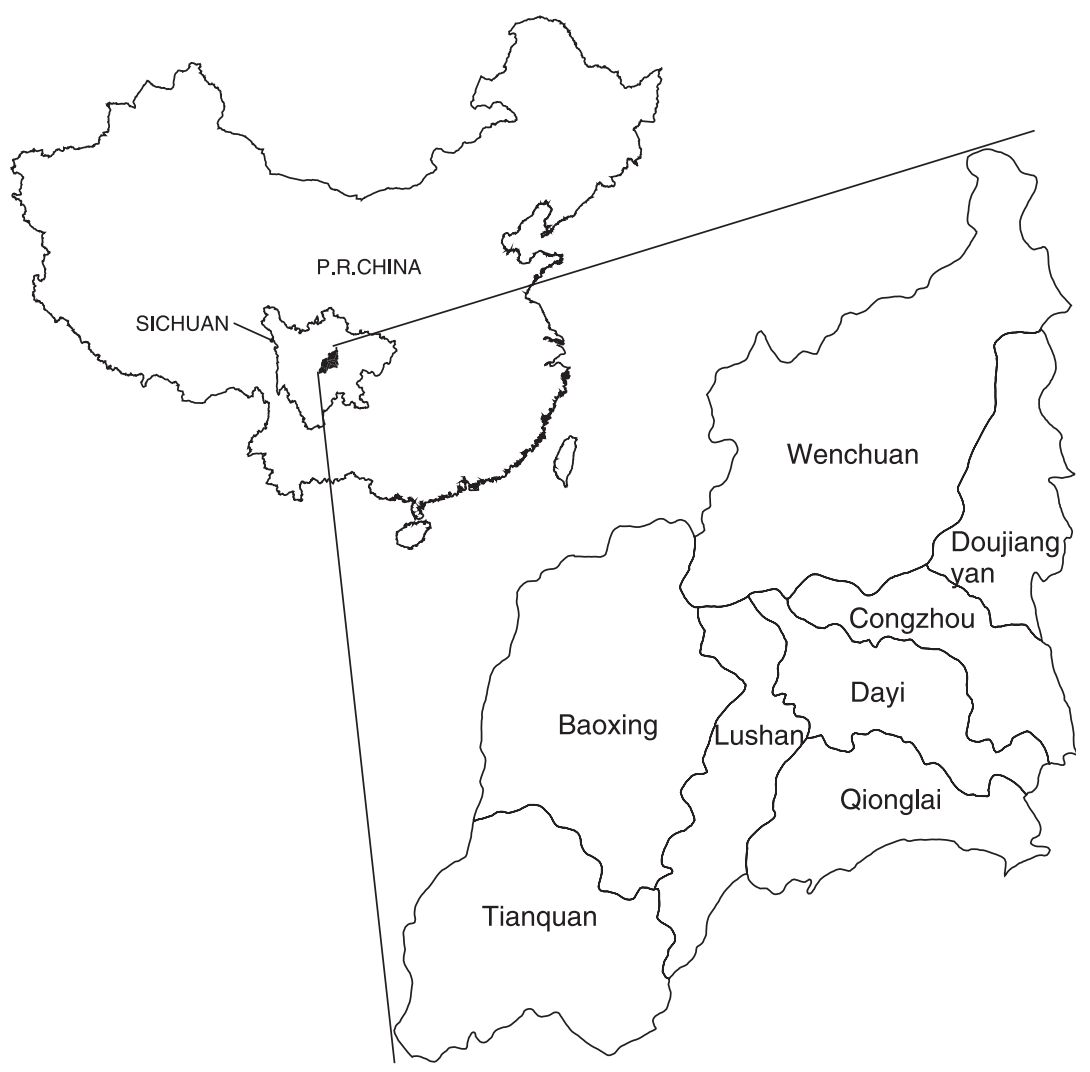

Figure 1 Location map of the study area comprising eight counties within the Sichuan province, China. are endangered and are listed as first class national protected animals of China (e.g. Neofelis nebulosa, B. taxicolor, Rhinopithecus roxellana, and Panthera pardus; Hu 1990, 2001).

In recent decades, commercial logging and agricultural expansion substantially decreased the forest cover in the Qionglai mountain range, from about $30 \%$ in the 1950 s to $16 \%$ in the 1980s (Gong \& Yu, 2003). Although commercial logging was banned since the implementation of the Natural Forest Conservation Program (NFCP) in 1998, its impact on panda habitat will last for some years (Ran et al., 2004). Other human activities, including road construction, urbanization, and mining, have further fragmented and degraded the habitat for the pandas (Hu, 2001). Today, habitat loss and fragmentation constitute the primary threats to the panda's survival in the wild (MacKinnon \& De Wulf, 1994; Pan, 1995; Linderman et al., 2005).

\section{Selection criteria for the assessment of giant panda's habitat}

Habitat for the pandas is defined as the area that provides food and shelter for foraging and reproduction. According to the conceptual framework established by Ouyang et al. (1995) and Liu et al. (1999), both biotic and abiotic conditions are important for assessing the potential of an area to be suitable habitat for the pandas.

The type of vegetation is one of the main biotic factors in defining habitat suitability. According to the 2nd NSPH, more than $80 \%$ of the evidence of panda activity found in the Qionglai mountain range occurred in conifer and broadleaf forests, with less than $20 \%$ in shrubs, and none in meadow and other land cover types (China's Ministry of Forestry \& WWF, 1989). Therefore, suitable habitat for the pandas should be comprised of a forest cover, although shrubs might also marginally constitute habitat for the pandas. Other land cover types are not suitable.

Bamboo availability and distribution are also considered important biotic factors for assessing if an area is suitable habitat for the pandas (Reid et al., 1989). Bamboo comprises about 99\% of the species diet. It has been reported that they spend up to $14 \mathrm{~h}$ per day foraging, due mostly to the low nutrient and energy content of bamboo (Schaller et al., 1985). In the Qionglai mountain range, giant pandas feed on several bamboo species, among which F. robusta, F. nitida, F. angustissima, Y. brevipaniculata, and Bashania faberi, are important food sources. Therefore, the areas where these species occur are also considered as suitable habitat for the pandas.

Important abiotic factors include elevation and slope. Giant pandas cannot tolerate the low temperatures, inadequate food supply, and type of vegetation cover present at high elevations (above $3750 \mathrm{~m}$ ). They also prefer flat areas or gentle slopes for ease of movement ( $\mathrm{Hu}, 2001)$.

Based on these biotic and abiotic factors that define an area as suitable habitat for the pandas, as well as on previous habitat researches in this mountain range (China's Ministry of Forestry \& WWF, 1989; Liu et al., 1999; Hu, 2001; 2004), we established different habitat suitability classes, as a multiplicative combination of four factors: type of vegetation, presence of understorey bamboo, elevation, and slope (Table 1). 
Table 1 Assessment of biotic and abiotic factors used to determine habitat suitability for the giant pandas in the Qionglai mountain range

\begin{tabular}{llll}
\hline Factor & Suitable & Marginally suitable & Unsuitable \\
\hline Vegetation & Forests & Shrubs & Other covers excluding forests and shrub \\
Bamboo & Bamboo & na & No bamboo \\
Elevation (m) & $>1500-=3250$ & $>1000-=1500->3250-=3750$ & $=1000 \mathrm{~m},>3750$ \\
Slope (degree) & $=30$ & $>30-=50$ & $>50$ \\
\hline
\end{tabular}

Table 2 Assessment of the effects of human factors on giant panda habitat

\begin{tabular}{|c|c|c|c|c|}
\hline \multirow[b]{2}{*}{ Factor } & \multicolumn{4}{|c|}{ Degree of effect } \\
\hline & Strong & Moderate & Weak & None \\
\hline Distance from major road $(\mathrm{m})$ & $=60$ & $>60-=210$ & $>210-=720$ & $>720$ \\
\hline Distance from minor road $(\mathrm{m})$ & na & na & $=30$ & $>30$ \\
\hline Distance from human settlements $(\mathrm{m})$ & $=900$ & $>900-=1410$ & $>1410-=1920$ & $>1920$ \\
\hline
\end{tabular}

Table 3 Final giant panda habitat suitability scheme resulting from the combination of a habitat qualification scheme* and human effects $\dagger$

\begin{tabular}{lllll}
\hline \multirow{2}{*}{$\begin{array}{l}\text { Quality of potential } \\
\text { giant panda habitat }\end{array}$} & Human effect & & & Weak \\
\cline { 2 - 5 } & Strong & Moderate & Marginally suitable & Suitable \\
\hline Suitable & Unsuitable & Marginally suitable & Marginally suitable & Marginally suitable \\
Marginally suitable & Unsuitable & Unsuitable & Unsuitable & Unsuitable \\
Unsuitable & Unsuitable & Unsuitable & & \\
\hline
\end{tabular}

${ }^{*}$ Based on biotic and abiotic habitat characteristics (Table 1).

$\dagger$ Based on Table 2.

Since human activities also cause habitat degradation, they need to be considered as well. Roads and human settlements are the most common and important human factors that affect the habitat for the giant pandas ( $\mathrm{Hu}, 2001)$. Construction of roads and human settlements not only decrease the areas of habitat, but also make the remaining habitat more fragmented. We assumed that the impacts of human activities on panda habitat decrease as a function of distance (Liu et al., 1999; Ouyang et al., 2001). Therefore, the impacts of human activities were divided into four classes based on changes in distance (Table 2). A final qualification of the habitat for the giant pandas in the study area was then obtained by adding up the impact of human activities (qualified by distance) with the biotic and abiotic characteristics previously described (Table 3 ).

\section{Vegetation mapping using satellite imagery}

Remote sensing is regarded as the most cost-effective tool for mapping the habitat for the giant pandas, particularly because access to the regions where the species occur is constrained by steep terrain and limited infrastructure (De Wulf et al., 1988; MacKinnon \& De Wulf, 1994). For mapping vegetation in the
Qionglai mountain range, we used cloud-free Landsat TM images $\left(30 \times 30 \mathrm{~m}^{2} /\right.$ pixel $)$ acquired in July 2001 by the China Remote Sensing Satellite Ground Station. The selection of this imagery was based entirely on cloud cover, because it is very difficult to find cloud-free images of the entire study area. The imagery was georeferenced to a WGS84 UTM coordinate system using the nearest neighbour algorithm. A supervised classification (into three classes: forest, shrub, and other) was carried out using the maximum likelihood classification algorithm (ERDAS Inc., 2001). For this, 100 ground truth points (out of 180 collected in the field from July to August of 2003 and September to November of 2004) were used as a training data set. All these analyses were performed in the ERDAS IMAGINE 8.5 software. We acknowledge that using field data collected in 2003-04 for training, a classification algorithm applied to imagery acquired in 2001 might be problematic, due to land cover changes that could have occurred between the two dates. Nevertheless, drastic changes in land cover (particularly those related to forest/nonforest transformation) have been reduced, owing mostly to the implementation of the Natural Forest Conservation Program (NFCP; Xu, personal observation), therefore decreasing the chances of misclassification errors. 
Table 4 Accuracy assessment of the classification of the 2001 Landsat TM images

\begin{tabular}{|c|c|c|c|c|c|}
\hline & \multicolumn{5}{|c|}{ Reference data } \\
\hline & Forests & Shrubs & Others & Row total & \% User's \\
\hline \multicolumn{6}{|c|}{ Classification data } \\
\hline Forests & 43 & 2 & 2 & 47 & 90 \\
\hline Shrubs & 6 & 10 & 2 & 18 & 63 \\
\hline Others & 3 & 1 & 11 & 15 & 69 \\
\hline Column total & 52 & 13 & 15 & 80 & \\
\hline$\%$ Producer's & 83 & 77 & 73 & & \\
\hline
\end{tabular}

Map accuracy $=80 \%$, Kappa coefficient $=0.63$.

Accuracy assessment was carried out using the remaining 80 ground truth points not used as training data set. Overall, producer's and user's accuracies as well as the Kappa coefficient were calculated (Congalton \& Green, 1999). Overall accuracy was $80 \%$ and the Kappa coefficient was 0.63 (Table 4). Errors induced by the potential land cover changes occurred between imagery acquisition and field data collection, as well as by the effects of shadows in steep areas, and by the potential confusion between young secondary forests and shrubs, account significantly to the reduction in classification accuracy (Table 4). However, the level of classification accuracy obtained in this study has also been reported in similar studies applied at the level of nature reserves (e.g. Liu et al., 2001) therefore we consider it enough for further giant panda habitat suitability analyses.

\section{Giant panda habitat assessment}

Analysis of the habitat suitability for the pandas was carried out according to the conceptual framework established by Ouyang et al. (1995) and Liu et al. (1999) and based on the criteria described previously. To calculate the different habitat suitability classes, we used the vegetation map obtained from the supervised classification of the Landsat TM imagery of 2001, slope and elevation information obtained from a $1: 50,000$ digital elevation model (DEM) acquired from the National Geomatics Center of China (NGCC) (resampled to match the 30-m pixel resolution of the Landsat image) and a coarse boundary map of bamboo distribution obtained from the survey report of the 2nd NSPH in the habitat assessment (China's Ministry of Forestry \& WWF, 1989). It should be pointed out that this map is suspected to overestimate the amount of area with bamboo understorey (Linderman, 2005), therefore future studies that establish a detailed and accurate description of bamboo distribution are urgently needed.

Distance from roads and human settlements was calculated based on digital maps of the road network and the location of human settlements. These digital maps were obtained from NGCC and were reclassified into four different human impact classes, based on distance (Table 2).

Values of 2, 1, and 0 were assigned to the classes 'suitable', 'marginally suitable', and 'unsuitable', respectively, in each of the four biotic and abiotic characteristics (Table 1). These four factors were then multiplied, producing a biotic/abiotic habitat map with values ranging from 0 to 16 . Pixels with a value of 0 were considered as unsuitable, whereas pixels with a value of 16 were considered as suitable. All other values in between were considered as marginally suitable. In this biotic/abiotic habitat map the unsuitable, marginally suitable, and suitable pixels were re-assigned to the values 0,1 , and 2, respectively.

A human impacts map was obtained from the different classes of human impact (Table 2). Values of $0,1,2$, and 3 were assigned to the classes 'strong', 'moderate', 'weak', and 'no human effects', respectively, in each of the three human impact variables (distance from major and minor roads, and to human settlements; Table 2). A single map was obtained by combining these three human impact variables by means of selecting the minimum value among the three. For instance, if a pixel is located $800 \mathrm{~m}$ from a major road (i.e. a value of 3), $25 \mathrm{~m}$ from a minor road (i.e. a value of 2) and $800 \mathrm{~m}$ from a human settlement (i.e. a value of 0 ), it would be considered under a strong human influence (i.e. a value of 0 ).

The product of the biotic/abiotic map with the human impacts map yielded a final habitat suitability map, with the values 0 and 1 being unsuitable habitat, 2, 3, and 4 being marginally suitable habitat, and 6 being suitable habitat. This final habitat suitability map was further modified by removing all small patches of isolated habitat. Patches with an area lower than 390 ha were excluded, based on the fact that previous research in Wolong Nature Reserve showed that the average home range for a single panda individual ranges between 390 and 620 ha (Hu, 2001). All these analyses were performed in ArcView 3.1.

\section{Selection of key and linkage areas}

Once the final habitat suitability map was produced, both key and linkage areas were identified. Key areas were identified in order to guide future conservation efforts and to potentially establish new nature reserves, these areas should contain large area of suitable habitats, with no or less human disturbances. Linkage areas were selected in order to provide passages for the movement of panda individuals among current nature reserves as well as among the different key areas identified. The identification of linkage areas was based on four criteria: (1) Elevation should be between 1500 and $3250 \mathrm{~m}$, since most of the evidence of giant panda activity were found within this altitudinal range (China's Ministry of Forestry \& WWF, 1989). (2) Average distance between habitat blocks should be less than $2 \mathrm{~km}$. Linkage areas are more effective if the distance between habitat blocks is less than the length of the maximum width of the average home range, so that giant panda individuals can pass through without foraging. Given an average home range size of 390 ha, with an average width of approximately $2 \mathrm{~km}$ ( $\mathrm{Hu}, 2001)$, this distance was selected. (3) Low density of human disturbances. Pandas tend to avoid humans and their activities, thus linkage areas should avoid high density of human activities. (4) Appropriate vegetation composition and forage. Linkage areas should be covered by forests with understorey bamboo. 
Figure 2 Giant panda habitat map of the Qionglai mountain range.

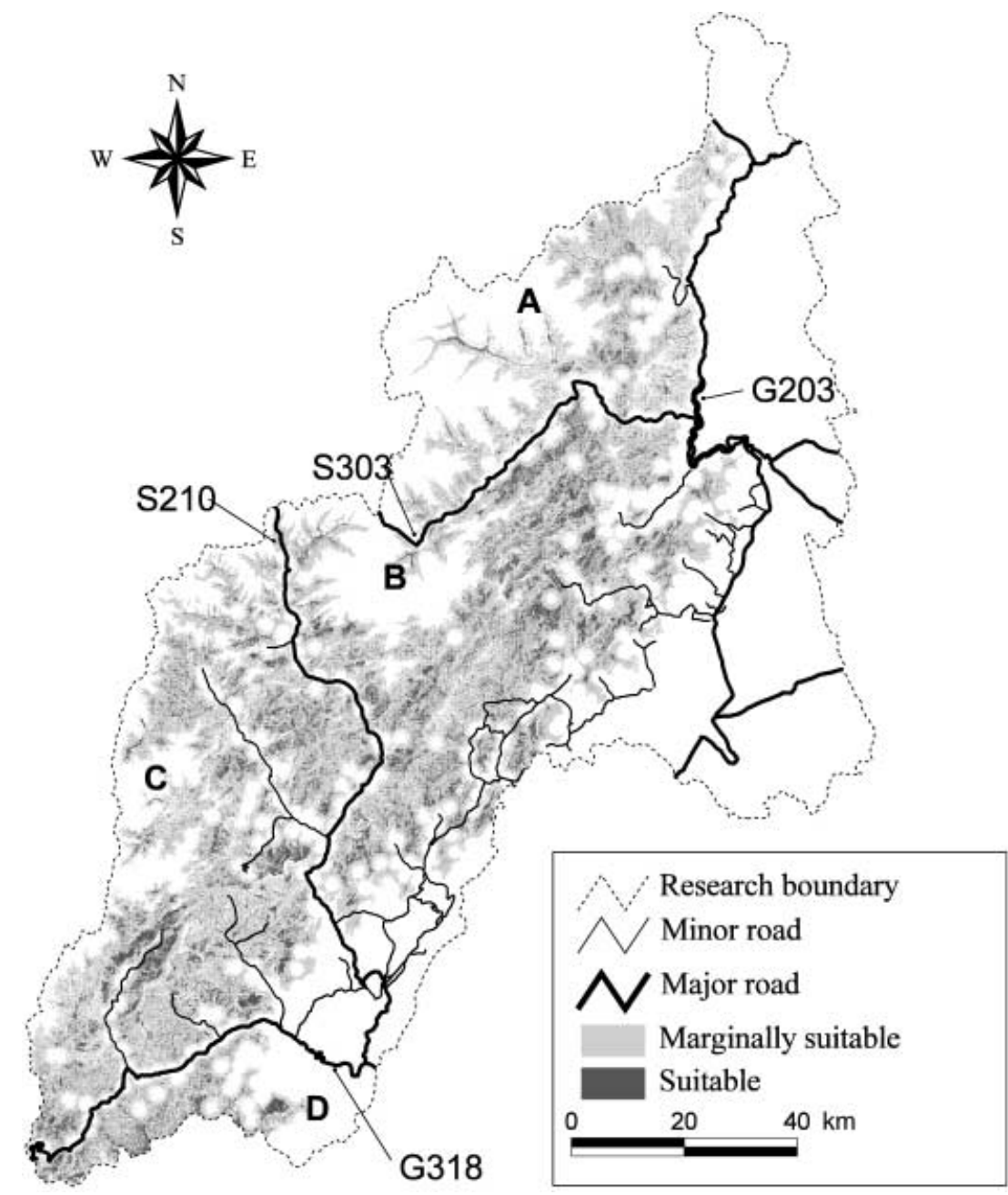

Table 5 Areas under different habitat blocks and their degree of protection in nature reserves

\begin{tabular}{|c|c|c|c|c|c|c|c|}
\hline \multirow[b]{2}{*}{ Block } & \multirow[b]{2}{*}{$\begin{array}{l}\text { Habitat } \\
\text { area (ha) }\end{array}$} & \multicolumn{2}{|c|}{ Suitable habitat } & \multicolumn{2}{|c|}{ Habitat in nature reserves } & \multicolumn{2}{|c|}{ Suitable habitat in reserves } \\
\hline & & Area (ha) & $\begin{array}{l}\text { Ratio to } \\
\text { habitat area (\%) }\end{array}$ & Area (ha) & $\begin{array}{l}\text { Ratio to } \\
\text { habitat area (\%) }\end{array}$ & Area (ha) & $\begin{array}{l}\text { Ratio to suitable } \\
\text { habitat area (\%) }\end{array}$ \\
\hline A & 69,360 & 8395 & 12 & 53,495 & 77 & 6729 & 80 \\
\hline B & 212,995 & 47,214 & 22 & 110,735 & 52 & 29,344 & 62 \\
\hline $\mathrm{C}$ & 193,781 & 40,287 & 21 & 18,308 & 9 & 5662 & 14 \\
\hline $\mathrm{D}$ & 29,955 & 7542 & 25 & 0 & 0 & 0 & 0 \\
\hline Total & 506,091 & 103,438 & 20 & 182,538 & 36 & 41,735 & 40 \\
\hline
\end{tabular}

\section{RESULTS}

\section{Giant panda habitat distribution}

The total area of giant panda habitat present in the Qionglai mountain range is around 506,091 ha (Table 5). This area includes both suitable (covering approximately 103,438 ha) and marginally suitable habitat (covering about 402,653 ha). The habitat in the Qionglai mountain range has been fragmented into four blocks (labelled from north to south as blocks A, B, C, and D; Fig. 2) by the provincial roads $\mathrm{S} 303, \mathrm{~S} 210$, the national road $\mathrm{G} 318$, and other human activities surrounding these roads, as well as rivers (Fig. 2). Blocks B and C comprise approximately $80 \%$ (406,776 ha) of the entire habitat and $85 \%$ (87,501 ha) of the suitable habitat (Table 5).

The habitat within each block is also fragmented by rivers, minor roads, and human impacts around them. For instance, the eastern part of block B is heavily fragmented while the western part has been kept almost intact. Block C seems to be isolated from the other blocks, but further research is required to determine its degree of isolation. 


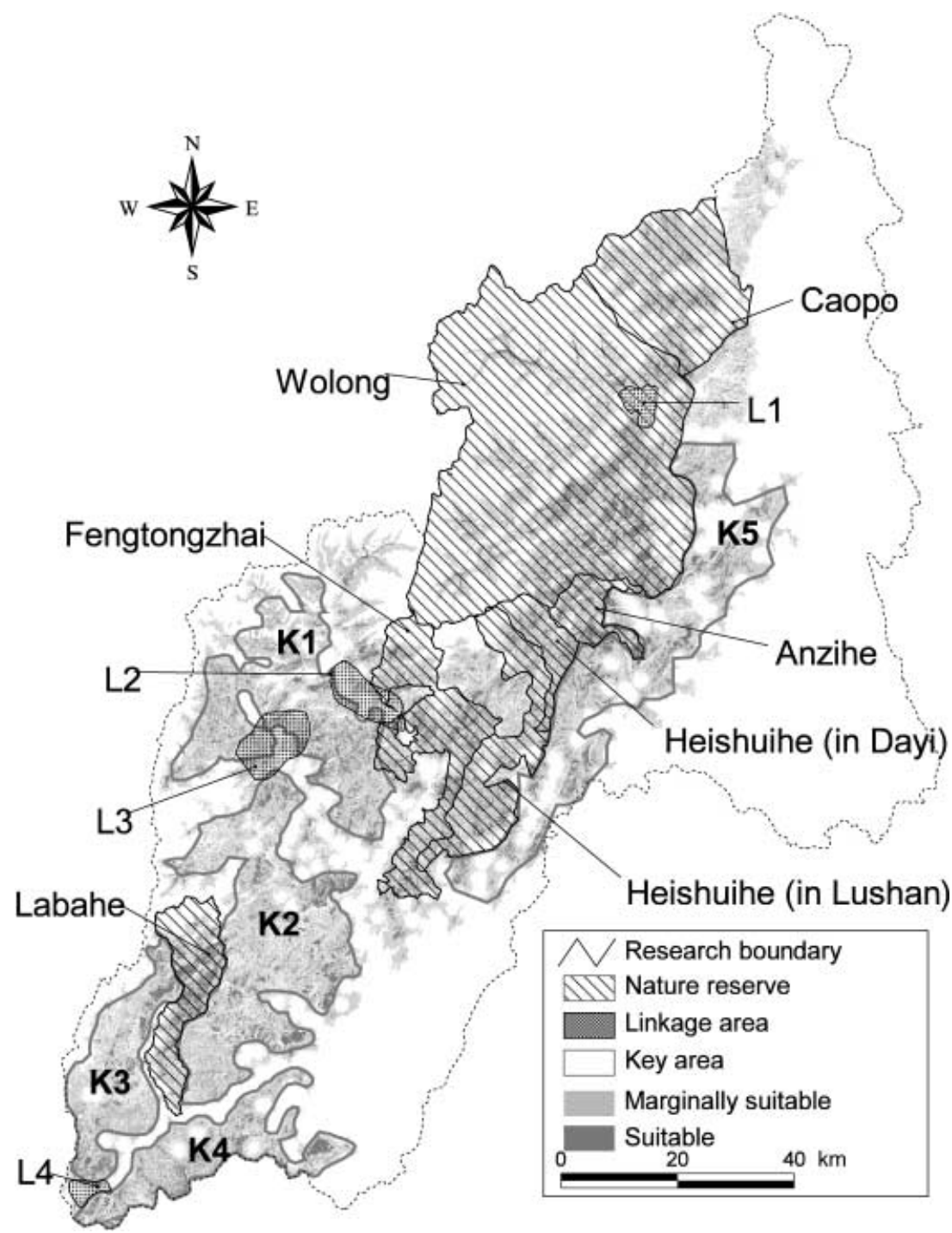

Figure 3 Proposed key and linkage areas for giant panda habitat conservation in the Qionglai mountain range. All key areas, as well as linkage areas L2, L3, and L4 are not protected under the current nature reserve network. Future conservation plans should incorporate these areas in order to facilitate the movement of giant panda individuals.

\section{Conservation status}

The current network of nature reserves in the Qionglai mountain range covers an area of about 381,600 ha, which provides protection for around $36 \%(182,538 \mathrm{ha})$ of the entire panda habitat, and for roughly $40 \%(41,735 \mathrm{ha})$ and $35 \%$ (140,803 ha) of the suitable and marginally suitable habitats, respectively. While more than half of the habitat present in blocks A and B is protected within nature reserves, less than $20 \%$ of the habitat present in block $\mathrm{C}$ is protected, and no habitat is currently under protection in block D (Table 5).

\section{Key areas for conservation of the remaining habitat}

By means of overlapping of habitat areas with the areas currently inside the nature reserve network, we identified five key areas (named K1 to K5) for potentially establishing additional nature reserves (Fig. 3). K1 lies in block C, to the west of Fengtongzhai Nature Reserve and the provincial road S210. This area includes the Yaoji Township that has been identified as being one of the centres of distribution of giant pandas in the Qionglai mountain range (Gong \& Yu, 2003). This conservation area is also required because Fengtongzhai Nature Reserve offers a small habitat protection for the habitat located in the eastern part of block C.

K2 lies to the east of Labahe Nature Reserve, whereas K3 lies to the west (Fig. 3). These areas lie at the central and western parts of block C, respectively, and are important for connecting Labahe Nature Reserve with other Nature Reserves located at the geographical centre of the Qionglai Mountain Range. K4 lies in block D, a block that does not have any current nature reserve. $\mathrm{K} 5$ lies in the eastern portion of block B, and may act as a buffer area for minimizing the human impacts on the existing five nature reserves located towards the west (Fig. 3).

\section{Linkage areas for connection of isolated habitat blocks}

Four areas (denoted L1 to L4) were identified as linkages between isolated or potentially isolated habitat blocks (Fig. 3). L1 is located inside Wolong Nature Reserve, with an elevation of 
around $2000 \mathrm{~m}$. Crossing provincial road S303, this area will connect blocks A and B within a distance of about $500 \mathrm{~m}$. Large areas of suitable habitat are distributed within blocks A and B around this area, and about 10 giant panda individuals have been reported to occur in the area (Gong \& Yu, 2003). This zone was also planned as a corridor after the 2nd NSPH; therefore, around 80 ha of bamboo were planted by the Wolong Nature Reserve Bureau in 2001, through the GTGP. This might provide food for the pandas potentially moving through this corridor.

L2 is located towards the west of Fengtong Zhai Nature Reserve, connecting blocks B and C across the provincial road S210 (Fig. 3). Distances between these two blocks are in general less than $1.5 \mathrm{~km}$. This area has elevations between 1800 and $2500 \mathrm{~m}$, and about $80 \%$ of it is covered with mixed conifer and broadleaf forests and with a bamboo understorey dominated by Fargesia angustissima, Phyllostachys nidularia, and Fargesia denudate (Gong \& Yu, 2003). This area is also within the influence of the GTGP and the NFCP of Tianquan County (Gong \& Yu, 2003), and its eastern part is enclosed by the Fengtongzhai Nature Reserve. Therefore L2 has a great promise for exchanging giant panda individuals between blocks $\mathrm{B}$ and $\mathrm{C}$.

L3 is located at the centre of block C. Elevation in this area is between 1500 and $3000 \mathrm{~m}$, with most areas covered by conifer and broadleaf forests. Few human settlements and cropland areas were seen in the area during the 2004 field data collection campaign. The establishment of L3 will benefit the exchange of panda individuals between $\mathrm{K} 1$ and $\mathrm{K} 2$.

L4 is located around the Erlang Mountain in the southwestern boundary of the study area. This area has an elevation between 2100 and $2800 \mathrm{~m}$ and no human settlements or cropland areas are present. Most of the area is covered by forests with bamboo understorey. Across the national road G318, this area will connect not only blocks C and D, but also Qionglai mountain range with the Xiangling mountain range. Although the national road G318 (originating in Shanghai and heavily used as a route to Tibet) effectively acts as a barrier for the movement of giant panda individuals between the Qionglai and Xiangling mountain ranges, its isolation effects might have been reduced by the recent construction of a tunnel in the Erlang Mountain (during 2004), which diverted traffic from the upper sections of the road. We expect that this tunnel will allow L4 to become a suitable area for dispersal of giant panda individuals between the Qionglai and Xiangling mountain ranges.

\section{DISCUSSION}

In this study, habitat assessment was carried out based on the framework developed by Ouyang et al. (1995) and Liu et al. (1999) and applied to information about biotic, abiotic, and human impact factors that affect the distribution of giant pandas. Information on elevation, slope, vegetation, bamboo distribution, roads, and human settlements was the main factors used for the assessment. However, our reliance on these as the primary factors influencing giant panda habitat was purely a function of data availability and does not mean that other factors are not of importance. Perhaps the largest information omission herein is the lack of detailed bamboo distribution data. Bamboo is a very important biotic characteristic in determining the distribution and quality of giant panda habitat because it constitutes their main food source (Reid et al., 1989). Unfortunately detailed information on bamboo distribution in the whole mountain range, but particularly outside nature reserves, is currently unavailable. This information is therefore of significant importance in future detailed habitat assessments.

Other human factors including herb collection, grazing, and tourism, should affect the distribution and quality of habitats. But such data were not available and causal relationships between these human activities and their effects on panda habitat still need to be established (Liu et al., 1999). Consideration of these factors could potentially enhance the accuracy of the analyses. Therefore, the habitat assessment in this study provides an overall coarse evaluation of the situation of panda habitat in the study area, rather than a definite habitat suitability map.

This assessment reveals broad fragmentation patterns of panda habitat in the Qionglai mountain range. In general, the entire habitat in this mountain range is separated into four blocks by major roads and surrounding human settlements and cropland areas. If the current situation of fragmentation in Qionglai mountain range continues, pandas will be separated into several isolated populations, which will increase the possibility of their extinction in the wild. Therefore, it is necessary to protect additional habitat blocks and create corridors among them and the current nature reserves.

Our results show that the current nature reserve network in the Qionglai mountain range only protects 36\% of the total habitat in the Qionglai mountain range. Furthermore, these nature reserves are mostly distributed in the northern and central parts of the study area, with only one nature reserve in the southern part. The agenda for the conservation and restoration of panda habitat in the Qionglai mountain range needs to increase the area of current nature reserves as well as to generate new nature reserves and corridors that facilitate the exchange of giant panda individuals among different habitat blocks. The proposed key and linkages zones, together with the current nature reserve network, will form a giant panda conservation unit in the Qionglai mountain range. $\mathrm{K} 1$ and $\mathrm{K} 2$ should become new nature reserves or extensions of current nature reserves due to the large area of habitat comprised within them and to their significant role in connecting Labahe Nature Reserve with other nature reserves in the region. K3 could become an extension of Labahe Nature Reserve. K4, together with L4, could be established either as nature reserves or as corridors connecting the Qionglai mountain range with the Xiangling mountain range, where the habitat for the giant panda is heavily isolated and the panda population is at the edge of extinction ( $\mathrm{Hu}, 2001$; Zhang \& $\mathrm{Hu}, 2004)$. K5 should become a new nature reserve or at least a buffer area, in order to alleviate the human impacts originated from the eastern plain area over the panda habitat within the nature reserves located towards the west (Fig. 3). L1 to L4 can be established as corridors between different habitat blocks, and these corridors could be an important part of the nature reserve 
network. Measures need to be taken to restore forests and bamboo understorey in these areas. Monitoring is also needed in different seasons to determine if giant pandas really use these corridors.

In summary, the key and linkage areas identified in this study, together with the nature reserves currently present in the study area constitute a management unit that enhances both the conservation and restoration of habitat for the giant pandas. This unit constitutes a practical way for managing the giant panda habitat present in the Qionglai mountain range, as well as its giant panda population. The environmental policies recently implemented by the Chinese government, including the Natural Forest Conservation Program (NFCP) and the Grain-to-Green Program (GTGP), could potentially aid in the formation and operation of such management unit.

\section{ACKNOWLEDGEMENTS}

This research was supported by the National Natural Science Foundation of China (30428028 and 40321101), and the US National Science Foundation (Biocomplexity in the Environment Grant). We thank Mr Jiang Zeyin and Mr Su Xiaobin, for their assistance during field data collection. We also acknowledge the Administration of Wolong Nature Reserve for their support with fieldwork logistics. We thank Erich W. Schienke and two anonymous referees for constructive suggestions to the manuscript.

\section{REFERENCES}

China's Ministry of Forestry and WWF. (1989) A comprehensive survey report on China's giant panda and its habitat. Chengdu.

Congalton, R.G. \& Green, K. (1999) Assessing the accuracy of remotely sensed data: principles and practices. Lewis, New York.

De Wulf, R.R., Goossens, R.E., MacKinnon, J.R. \& Wu, S.C. (1988) Remote Sensing for Wildlife Management: giant panda habitat mapping from LANDSAT MSS images. Geocarto International, 1, 41-50.

Erdas, Inc., (2001) Erdas imagine tour guides. Erdas Imagine V8.5. In: Erdas, Inc., Atlanta, Georgia.

Gong, M. \& Yu, C. (2003) Study on the corridors of giant panda. China Forestry Publishing House, Beijing.

$\mathrm{Hu}$, J. (1990) Research and progress in biology of giant panda. Sichuan Publishing House of Science and Technology, Chengdu.

$\mathrm{Hu}$, J. (2001) Research on the giant panda. Shanghai Science and Technology Education Press, Shanghai.

$\mathrm{Hu}$, J. (2004) Population and conservation of giant pandas in Wolong and Caopo nature reserves. Acta Theriologica Sinica, $24,48-52$.

Linderman, M.A., An, L., Bearer S., He, G., Ouyang, Z. \& Liu, J. (2005) Modeling the spatio-temporal dynamics and interactions of households, landscapes, and giant panda habitat. Ecological Modelling, 183, 47-65.

Liu, J., Ouyang Z., Yang, Z., Taylor, W., Groop, R., Tan, Y. \& Zhang, H. (1999) A framework for evaluating the effects of human factors on wildlife habitat: The case of giant pandas. Conservation Biology, 13, 1360-1370.

Liu, J., Linderman, M., Ouyang, Z., An, L., Yang, J. \& Zhang, H. (2001) Ecological degradation in protected areas: the case of Wolong Nature Reserve for giant pandas. Science, 292, 98101.

Liu, J., An, L., Bearer S., Chen, X., He, G., Jenkins, C., Linderman, M., Ouyang, Z. \& Zhang, H. (2004) Complex interactions among people, policies and panda habitat. Symposium on Frontiers in Biocomplexity Sciences: Reciprocal Interactions Between Human and Natural Systems. Annual meeting of the American Association for the Advancement of Science, Seattle, February, 2004.

Loucks, C.J., Lü, Z., Dinerstein, E., Wang, H., Olson, D.M., Zhu, C. \& Wang, D. (2001) Giant pandas in a changing landscape. Science, 294, 1465.

Loucks, C.J., Lü, Z., Dinerstein E., Wang, D., Fu, D. \& Wang, H. (2003) The giant pandas of the Qinling mountains, China: a case study in designing conservation landscapes for elevational migrants. Conservation Biology, 17, 558-565.

MacKinnon, J. \& De Wulf, R. (1994) Designing protected areas for giant pandas in China. Mapping the Diversity of Nature (ed. by R.I. Miller), pp. 127-142. Chapman \& Hall, London.

Ouyang, Z., Zhang, H. \& Tan, Y. (1995) Application of Geographic Information Systems in assessment of giant panda habitat in Wolong Nature Reserve. China Man and Biosphere, $3,8-12$.

Ouyang, Z., Liu. J., Xiao, H., Tan Y. \& Zhang H. (2001) An assessment of giant panda habitat in Wolong Nature Reserve. Acta Ecologica Sinica, 21, 1869-1874.

Pan, W. (1995) New hope for China's giant panda. National Geographic, 193, 100-115.

Pan, W., Lü. Z., Wang, D. \& Wang, H. (2001) The opportunity for the giant panda to exist. Peking University Press, Beijing.

Ran, J., Zeng, Z., Wang, H., Liu, S., Wang, H. \& Liu, S. (2004) A comparative study on habitat preference of giant pandas in primary and secondary forests. Journal of Beijing Forestry University, 26, 8-14.

Reid, D.G., Hu, J., Dong, S., Wang, W. \& Huang, Y. (1989) Giant panda Ailuropoda melanoleuca behaviour and carrying capacity following a bamboo die-off. Biological Conservation, 49, 85-104.

Schaller, G.B., Hu, J., Pan, W. \& Zhu, J. (1985) The giant pandas of Wolong. Chicago and London, University of Chicago Press, Chicago, Illinois.

State Forestry Administration, P. R. China. (2004) Individuals of giant panda increased: a review on the third national survey of pandas and habitat. (http://www.forestry.gov.cn/DB/news/ content.asp?table_type $=$ news\&id $=14784 \&$ pgid $=2$ ).

State Forestry Administration, P. R. China. (2005) Six important programs of forestry. (http://www.forestry.gov.cn/SHTGC/ index.asp).

Xinhuanet (2004) State forestry administration: population number of giant panda in the wild reaches about, 1590. http:// news.xinhuanet.com/video/(2004)-06/10/content_1518581.htm. (Last accessed 10 June 2004). 
Yan, X., Deng, X., Zhang, H., Lam, M., Ellis, S., Wildt D., Miller, P. \& U.S. Seal. (2000) Giant panda conservation assessment and research techniques: workshop final report. World Conservation Union/Species Survival Commission, Conservation Breeding Specialist Group, Apple Valley, Minnesota.
Zhang, Z. \& Hu, J. (2004) Population dynamics of the giant panda in the Daxiangling Mountains according to PVA. Journal of Sichuan Teachers College (Natural Science), 24, 141-144.

Zhu, C. \& Feng. G. (2002) A case study on China's policy of converting steep cultivated land to forest or grassland. China's Forestry Press, Beijing. 